\title{
Ecology of tropical hermit crabs at Quirimba Island, Mozambique: vertical migration (tree climbing)
}

\author{
David K. A. Barnes* \\ Frontier Moçambique, Caixa Postal 19, Pemba, Cabo Delgado, Mozambique \\ and
}

Society for Environmental Exploration, 77 Leonard Street, London EC2A 4QS, United Kingdom

\begin{abstract}
The semi-terrestrial hermit crabs Coenobita cavipes and Coenobita rugosus both undertake vertical migrations at Quirimba Island, Mozambique, by tree climbing in the region between High Water Neap tide level and Extreme High Water Spring tide level. Both species occurred in mangrove trees at all states of light:dark and tidal cycles, although more crabs were present in the study trees at high water than low water. The consecutive period of time spent in trees by $C$. cavipes individuals var. ied between half a tidal cycle $(<6 \mathrm{~h})$ and 2 complete tidal cycles $(24 \mathrm{~h})$. The vertical distance climbed varied between $5 \mathrm{~cm}$ and $4 \mathrm{~m}$, but $C$. cavipes climbed significantly higher than $C$. rugosus. The height climbed by $C$. cavipes was irrespective of whether the tide actually reached within $10 \mathrm{~m}$ of the tree being climbed. Mean climb height was related to the size of $C$. cavipes individuals, such that maxima were achieved by those of mid-sized mass. Shell species used also influenced the climb height. High wind speeds (force 3 to 5 or 12 to $33 \mathrm{~km} \mathrm{~h}^{-1}$ ) had a negative influence on the mean number of hermit crabs climbing. Species of mangrove tree, degree of shade, number of roots and root ground area were all found to be insignificant as influences, but the mean number of hermit crabs per tree increased from 0.43 in those with no trunk or branch holes to 5.08 in those with 5 or 6 holes. There were marked activity and behavioural differences between hermit crabs taking residence in trunk/branch holes and those clinging to branches or leaf bases. Shell exchange in tree hole gatherings (where up to 30 individuals were present), as opposed to ground based shell exchange, may have advantages in reducing desiccation (there is sometimes additionally a supply of fresh water), reducing the risk of predation and not reducing feeding time.
\end{abstract}

KEY WORDS: Hermit crab $\cdot$ Migration $\cdot$ Tree climbing $\cdot$ Mangrove $\cdot$ Africa $\cdot$ Clustering

\section{INTRODUCTION}

The Coenobitidae (Anomura, Decapoda) are amongst the most terrestrially adapted Crustacea, along with some representatives of the brachyuran taxa Gecarcinidae, Grapsidae, Potamoidea and Ocypodidae. Although the Coenobitidae are widely distributed throughout the tropical and subtropical regions, they achieve greatest diversity in the Indo-West Pacific (Burggren \& McMahon 1988). Coenobita cavipes and

\footnotetext{
-Address for correspondence: Department of Zoology and Animal Ecology, University College Cork, Lee Maltings, Cork,Ireland.E-mail: dkab@ucc.ie
}

Coenobita rugosus are 2 abundant Indo-Pacific species of hermit crab which are capable of climbing trees (De Wilde 1973). Tree climbing crabs have generally been divided into 4 basic types: (1) those that are basically ground living but occasionally venture up mangrove trees, (2) those which are basically tree living and occasionally venture to ground, (3) those which are exclusive tree dwellers inhabiting part of the tree and (4) those which are exclusively tree dwellers inhabiting all of the tree (Ruwa 1990, Vannini \& Ruwa 1994, Vannini et al. in press). The tree climbing habit of $C$. rugosus, which belongs to the first of these groups (as does $C$. cavipes), has been described as providing a refugial habitat in addition to burrows, crevices 
and root dwellings (De Wilde 1973, Vannini 1975, 1976).

In the Quirimba Archipelago of tropical northern Mozambique the small near-shore islands have wide intertidal zones, a large range of habitat types and an abundance and diversity of hermit crabs. Coenobita cavipes and $C$. rugosus are the most landward of 16 species of hermit crab which inhabit the intertidal region of the archipelago (Barnes 1997). Here $C$. cavipes occurs only in or close to mangrove forests and $C$. rugosus generally occurs on open areas of the supra-littoral such as beach or scrub vegetation, as has been described for more northerly East African populations (Vannini 1976, Lewinsohn 1982). On Quirimba Island, the 2 species overlap on a stretch of coast, which has a thin veil of mangrove forest, and show both unusually extended periods of activity and distinct differences in activity with habitat type (Barnes 1997).

The study reported here describes the climbing behaviour of Coenobita cavipes and C. rugosus, including species proportions of climbing individuals with circadian and tidal changes, the shore sub-zonal location of most intense climbing behaviour, the period spent by hermit crabs in arboretum and the vertical distance climbed. Possible endogenous and exogenous influences on tree climbing by hermit crabs at Quirimba Island were investigated, including circadian and tidal rhythms, wind speed, biological characteristics of mangrove trees and the shell species carried by crabs. Observations are also given on hermit crab behaviour associated with or performed whilst climbing and the purposes of such activity discussed. This work forms part of the marine research programme of the Darwin/Frontier Mozambique project of the Society for Environmental Exploration and the Ministépara a Coordenação de Acção Ambiental (Maputo, Mozambique).

\section{METHODS}

The vertical migrations (tree climbing activity) of 2 species of hermit crabs were studied in the mangrove forests of Quirimba Island, northern Mozambique $\left(12^{\circ} 42^{\prime} \mathrm{S}, 40^{\circ} 50^{\prime} \mathrm{E}\right)$. The fieldwork was carried out at the Darwin/Frontier Mozambique station on Quirimba Island between July and September 1996. The study area was the supra-littoral margin of an exposed mangrove forest approximately $400 \mathrm{~m}$ wide and dominated by Rhizophora trees; for map and further details see Barnes (1997). The tree height ranged from 4 to $8 \mathrm{~m}$ in height and from 1 to 5 per $4 \mathrm{~m}^{2}$ in density. The substratum was a mud-sand mixture, but the particle size range was not measured. Two species of hermit crab were studied, Coenobita cavipes and C. rugosus. These species are easily distinguishable in the field by examination of the outer surface of the major chela, on which C. rugosus has a pronounced series of ridges (Lewinsohn 1982). Both species were locally abundant on Quirimba Island but confined to the supra-littoral zone (Barnes 1997).

A sample of 42 mangrove trees (36 Rhizophora mucronata and 6 Brugiera gymnorhiza) were monitored for hermit crab migrations over a continuous period of $21 \mathrm{~d}$. The species of tree, ground area of roots, number of trunk holes and position relative to mean high water level were recorded for each of the sample trees. The identity and number of hermit crabs present on each tree were examined at every low and high tide throughout the study period. The wind speed (Beaufort scale), but not direction, on each occasion was also recorded. In a separate experiment, the large chela of each of 270 hermit crabs found in trees was marked with a pencil. The position of each crab and the occupied tree identity were recorded. One pencil mark was added for each complete change of tidal state (either low or high tide) so that the approximate time and number of tidal sequences that crabs spent in trees could be investigated. The climb height of hermit crabs was measured in a random sample of a variable number of trees (from 20 to 45) from each of 4 zones. The measurement was relative to the high water level ( 5 to $10 \mathrm{~m}$ below the high water mark (HWM), 0 to $5 \mathrm{~m}$ below the HWM, 0 to $5 \mathrm{~m}$ above the HWM and 5 to $10 \mathrm{~m}$ above the HWM]. The height measurement was taken as that from the base of the crab to the level of daily high water ( $\mathrm{HW}$; not the height from the ground). Climb-height measurements of both species were collected during 2 low water neap tides (LWN), 2 high water neap tides (HWN) and 2 high water spring tides (HWS) for both diurnal and nocturnal periods.

\section{RESULTS}

The hermit crabs Coenobita cavipes and C. rugosus were both observed to undertake vertical migrations by tree climbing and crawling up and down the beach throughout the study area between HWN and Extreme High Water Spring tide (EHWS) levels, referred to here as the supra-littoral. Although both species accurred above EHWS, no tree climbing activity by either species was observed above EHWS. Clibanarius longitarsus, the only other of 16 species of hermit crabs from Quirimba Island described (Barnes 1997) to inhabit the supra-littoral zone, was not observed to undertake any vertical migrations during the study period. The proportions of the tree climbing population of $C$. cavipes and $C$. rugosus were approximately 91 and $9 \%$ respec- 
Table 1 Coenobita cavipes and Coenobita rugosus. Species proportions of hermit crab tree climbing and ground populations at day and night, high and low water. Values for the 2 species are daily means (SE in parentheses). Total number of crabs sampled $=998$. Total number of sample days $=21$. Chi-squared values are given for tests between tree and ground populations: $p<0.05$ $\cdots p<0.01, \cdots p<0.001$

\begin{tabular}{|c|c|c|c|c|c|c|}
\hline \multirow[t]{2}{*}{ Time } & \multirow[t]{2}{*}{ Tidal state } & \multicolumn{2}{|c|}{ Tree population } & \multicolumn{2}{|c|}{ Ground population } & \multirow[t]{2}{*}{$\chi^{2}$} \\
\hline & & $\begin{array}{l}\text { C. cavipes } \\
(\mathrm{n}=471)\end{array}$ & $\begin{array}{c}\text { C. rugosus } \\
(\mathrm{n}=36)\end{array}$ & $\begin{array}{l}\text { C. cavipes } \\
(\mathrm{n}=309)\end{array}$ & $\begin{array}{l}\text { C. rugosus } \\
(\mathrm{n}=182)\end{array}$ & \\
\hline \multirow[t]{2}{*}{ Day } & High water & $91.8(1.5)$ & $8.2(1.5)$ & $63.1(0.8)$ & $36.9(0.8)$ & $108.9 * \cdots$ \\
\hline & Low water & $90.8(3.8)$ & $9.2(3.8)$ & $62.2(1.0)$ & $37.8(1.0)$ & $94.9 \cdots$ \\
\hline \multirow[t]{2}{*}{ Night } & High water & $89.5(1.3)$ & $10.5(1.3)$ & $62.0(2.3)$ & $38.0(2.3)$ & $77.8^{\cdots}$ \\
\hline & Low water & $93.0(2.5)$ & $7.0(2.5)$ & $63.2(0.8)$ & $36.8(0.8)$ & $104.9 \cdots$ \\
\hline
\end{tabular}

tively, irrespective of light:dark cycle or tidal conditions (Table 1). The proportions of the ground populations of the 2 species were more closely balanced (approximately 63 and $37 \%$ respectively). N.B. C. cavipes was overall more numerous than C. rugosus - see Barnes (1997). Significantly more individuals of $C$. cavipes than C. rugosus climbed trees irrespective of tidal conditions in this habitat. Both species occurred in trees at all states of light:dark and tidal cycles, although more crabs were present in the study trees at high water than low water, significantly so diurnally (Table 2). The density of crabs per tree decreased away from the HWM up and down shore such that no crabs climbed trees further than $10 \mathrm{~m}$ horizontal distance from the HWM. The light:dark and tidal cycle differences, in numbers of crabs per tree, were statistically non significant (and thus probably less important than shore position). Although the tree population was higher at high water

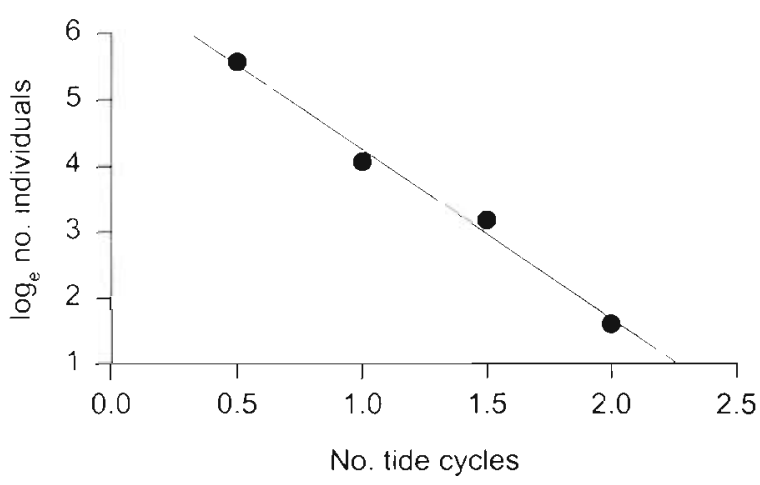

Fig. 1. Coenobita cavipes. Continuous duration of stay in mangrove trees by hermit crabs. Number of individuals ( $\left.\log _{e}\right)$ is shown with the number of continuous tidal cycles spent in trees. Regression line equation: $\log$ (no. of individuals) = -2.56 (no. of tidal cycles) +6.8 . ANOVA, $F=194.5, p<0.005$
Table 2. Coenobita cavipes. Mean $( \pm \mathrm{SE})$ number of hermit crabs per tree with distance from the High Water Mark (HWM) and circadian and tidal per tree was significantly related to the distance from HWM as shown by the ANOVA values $" p<0.05, \cdots p<0.01$ and $\cdots p<0.001$. The number of crabs per tree was significantly different between high water (HW) day and low water (LW) day (ANOVA, $F=10.93 \cdots$ ). All other comparisons showed non significant differences

\begin{tabular}{|lllll|}
\hline $\begin{array}{l}\text { Distance from } \\
\text { HWM }(\mathrm{m})\end{array}$ & $\begin{array}{l}\text { HW day } \\
(\mathrm{n}=299)\end{array}$ & $\begin{array}{l}\text { LW day } \\
(\mathrm{n}=295)\end{array}$ & $\begin{array}{l}\text { HW night } \\
(\mathrm{n}=291)\end{array}$ & $\begin{array}{l}\text { LW night } \\
(\mathrm{n}=274)\end{array}$ \\
\hline $10-15 \mathrm{~B}$ & 0 & 0 & 0 & 0 \\
$5-10 \mathrm{~B}$ & $0.17(0.05)$ & $0.08(0.02)$ & $0.49(0.23)$ & $0.19(0.07)$ \\
$0-5 \mathrm{~B}$ & $0.74(0.29)$ & $0.45(0.05)$ & $1.15(0.22)$ & $1.05(0.26)$ \\
$0-5 \mathrm{~A}$ & $1.68(0.28)$ & $0.56(0.05)$ & $1.04(0.31)$ & $0.77(0.24)$ \\
$5-10 \mathrm{~A}$ & $0.14(0.06)$ & 0 & $0.05(0.03)$ & $0.07(0.04)$ \\
$10-15 \mathrm{~A}$ & 0 & 0 & 0 & 0 \\
ANOVA & $9.29 \cdots$ & $3.83 \cdots$ & $3.33^{\circ}$ & $8.23 \cdots$ \\
\hline
\end{tabular}

than low, this difference was only significant during the day (Table 2). The peak density per tree in darkness (1.05 to 1.15 individuals per tree) was half way between the peak densities per tree at low and high water during daylight. The consecutive period of time spent in trees by $C$. cavipes individuals varied between half a tidal cycle $(<6 \mathrm{~h})$ and 2 complete tidal cycles ( $24 \mathrm{~h}$ ). The continuous time spent in trees by individuals exponentially decreased with time over this period, measured here by the consecutive number of tidal cycles (Fig. 1).

The vertical distance climbed by Coenobita cavipes varied between $5 \mathrm{~cm}$ and $4 \mathrm{~m}$ while that of $C$. rugosus varied between $5 \mathrm{~cm}$ and $1.5 \mathrm{~m}$ above HW. Generally, though, both species climbed to between 40 and $100 \mathrm{~cm}$. Although the mean climb heights illustrated in Table 3 are of greater magnitude at high water than low, this was only statistically significant at night on neap tides. There was little or no difference between light and dark climb heights at comparable tidal states in either species. C. cavipes climbed significantly higher $(31.6 \mathrm{~cm}$ on average, Student's $t, p<0.05)$ than 
C. rugosus on all but day high neap tides. Although the behaviour of tree climbing was restricted to $10 \mathrm{~m}$ either side of the HWM (Table 2), the height climbed within this zone varied little with shore height or tide magnitude (Table 4). Thus the height climbed by C. cavipes was irrespective of whether the tide actually reached within $10 \mathrm{~m}$ of the tree being climbed. The mass of individual $C$. cavipes also significantly influenced the height climbed (Fig. 2). The magnitude of mean climb height peaked at $106 \mathrm{~cm}$, with mid-sized individuals $(4 \mathrm{~g})$, and decreased with decreasing crab mass to approximately half the peak value for the
Table 3. Coenobita cavipes and Coenobita rugosus. Mean ( \pm SE) vertical climb distance (above daily high water) of hermit crabs with circadian and tidal states. nd: no data were recorded during low water spring tides. Minimum sample size of individual means: $C$. cavipes $=70$, C. rugosus $=6$. All C. cavipes climb-height pairwise comparisons were statistically non significantly different except night HW neap vs night LW neap (ANOVA, $F=7.89$, $p<0.01$ ). All $C$. rugosus climb-height pairwise comparisons were non significantly different

\begin{tabular}{|c|c|c|c|c|c|}
\hline \multirow[t]{3}{*}{ Time } & \multirow[t]{3}{*}{ Tidal state } & \multicolumn{4}{|c|}{ Vertical climb distance $(\mathrm{cm})$} \\
\hline & & \multicolumn{2}{|c|}{ C. cavipes } & \multicolumn{2}{|c|}{ C. rugosus } \\
\hline & & Neap & Spring & Neap & Spring \\
\hline \multirow[t]{2}{*}{ Day } & High water & $85.2(5.6)$ & $100.7(5.8)$ & $70.7(13.4)$ & $67.0(21.3)$ \\
\hline & Low water & $76.3(6.7)$ & nd & $40.0(12.2)$ & nd \\
\hline \multirow[t]{2}{*}{ Night } & High water & $80.2(4.6)$ & $92.0(8.9)$ & $51.5(9.1)$ & $54.0(4.8)$ \\
\hline & Low water & $62.6(4.1)$ & nd & $41.3(7.4)$ & nd \\
\hline
\end{tabular}

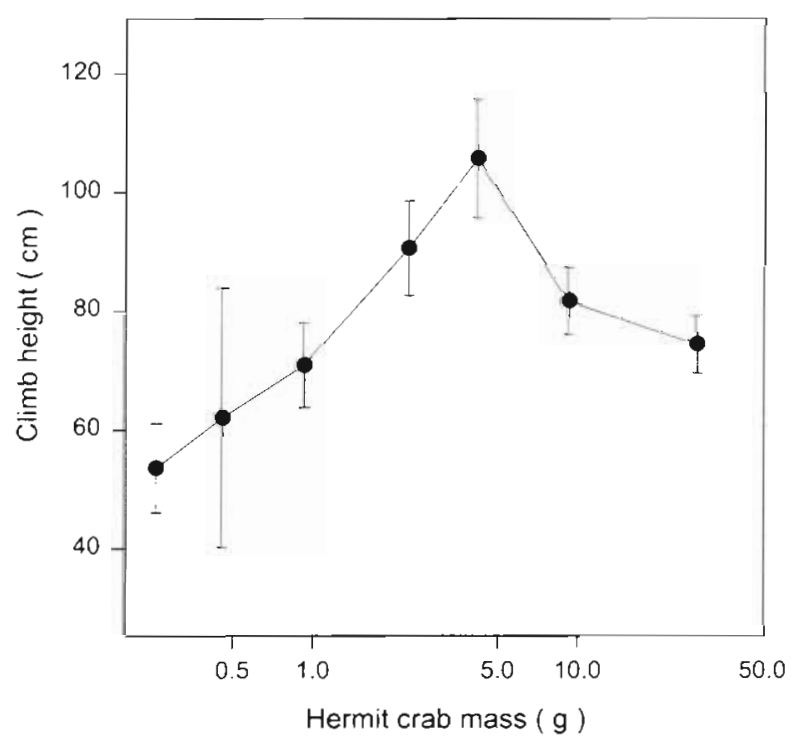

Fig. 2. Coenobita cavipes. Mean ( $\pm \mathrm{SE})$ climb height in relation to log body mass of hermit crabs. Sample size ranged from 10 (minimum, $0.5 \mathrm{~g}$ size class) to 48 (maximum, $5 \mathrm{~g}$ size class). Climb height significantly varied with log body mass (ANOVA, $F=3.4, \mathrm{p}<0.01$ )

Table 4. Coenobita cavipes. Mean $( \pm S E)$ vertical climb distance of hermit crabs with shore height and tidal state. No SE is shown for high water spring at $5-10 \mathrm{~m}$ below the HWM as the value represents only 1 record. For all other combinations, $n>5$ and ANOVA companisons were statistically non significant $(p>0.05)$

\begin{tabular}{|lccc|}
\hline $\begin{array}{l}\text { Distance from } \\
\text { HWM (m) }\end{array}$ & \multicolumn{2}{c}{$\begin{array}{c}\text { Vertical climb distance }(\mathrm{cm}) \\
\text { High water spring }\end{array}$} & $\begin{array}{c}\text { ANOVA } \\
(F \text { value })\end{array}$ \\
\hline $5-10 \mathrm{~B}$ & $100(-)$ & $94.0(11.1)$ & - \\
$0-5 \mathrm{~B}$ & $112.5(7.2)$ & $94.4(5.1)$ & 3.7 \\
$5-0 \mathrm{~A}$ & $72.5(6.2)$ & $85.6(5.1)$ & 3.0 \\
10-5 A & $93.6(18.4)$ & $75.0(13.9)$ & 2.3 \\
\hline
\end{tabular}

smallest size group measured $(0.25 \mathrm{~g})$. With increasing mass from $4 \mathrm{~g}$, the climb height decreased to $74 \mathrm{~cm}$ in the largest size group ( $28 \mathrm{~g}$ ). The mean climb height of $C$. cavipes also significantly differed with species of shell carried (ANOVA, $F=3.87, \mathrm{p}<0.01$ ), but any such relationship is complicated by a relationship between species of shell used and hermit crab size. Shell species used by $C$. rugosus, however, did not significantly influence tree climbing behaviour (ANOVA, $F=0.18, p$ $>0.05)$. The proportions of the tree climbing population of both species bearing certain shell species (e.g. Turbo coronatus) were different to the ground population, whereas the proportions of those using others (e.g. Terebralia palustris) were similar (Table 5). Tree climbing $C$. cavipes individuals using $T$. coronatus shells formed approximately twice the population proportion that they did in the ground population. $C$. rugosus individuals using $T$. coronatus shells, in contrast, formed approximately half the population proportion that they did in the ground population.

There was considerable variation between the hermit crab populations of the 42 monitored trees during the $21 \mathrm{~d}$ study period. Whilst some trees were unoccupied for virtually the whole study period, others had up to 30 individuals during a single tide. There were, however, distinct periods of higher and lower levels of climbing activity. During this period the wind speed varied between force 0 and 5 on the Beaufort scale. At the lower levels of wind velocity (below force 3 or $12 \mathrm{~km} \mathrm{~h}^{-1}$ ), which accounted for $85 \%$ of the study period, there was little or no detected influence of wind on the number of hermit crabs per tree or the number of occupied trees within the study population. Wind speeds of greater magnitude (force 3 to 5 or 12 to $33 \mathrm{~km} \mathrm{~h}^{-1}$ ), however, were a major influ- 
ence on the mean number of hermit crabs climbing (Fig. 3a) in the study location. The mean number of occupied trees was also much lower during higher wind speeds but there was a high degree of variation (Fig. 3b).

Species of mangrove tree, degree of shade, number of roots and root ground area were all found to be non significant (ANOVAs, all cases p > 0.05) as influences on the proportion of trees unoccupied by hermit crabs or the mean number of crabs per tree. The number of trunk or branch holes in a given tree, however, had an important effect (Fig. 4). N.B. The trunk and branch holes measured were all in intact trees, above the HWM and of unknown origin. The mean number of hermit crabs per tree increased from 0.43 in those with no holes to 5.08 in those with 5 or 6 holes. There were also marked activity and behavioural differences between hermit crabs taking residence in trunk/branch holes and those clinging to branches or leaf bases. Virtually all Coenobita cavipes and C. rugosus in both situations adopted a stage of semi-withdrawn dormancy after having reached the peak climb height; they remained semi-withdrawn until descent, which was accomplished by climbing or, if disturbed, by just dropping. C. cavipes and C. rugosus individuals which climbed into tree holes would also assume semi-dormancy, unless either a water pool or other individuals were present. Both species used the water to re-supply, but $C$. cavipes individuals became highly active in mutual shell inspection and even shell trading in holes

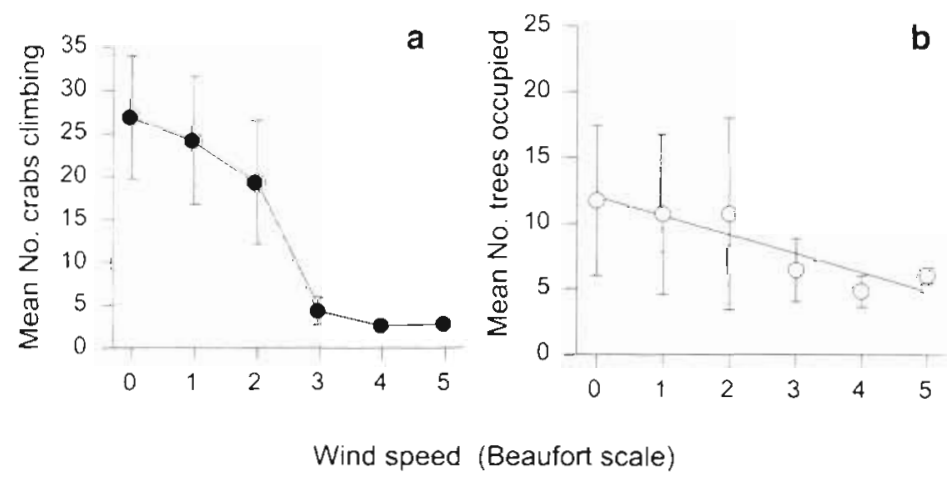

Fig. 3. Coenobita cavipes and Coenobita rugosus. Influence of wind speed on tree climbing by hermit crabs. (a) Mean total number of hermit crabs in mangrove trees and (b) mean number of mangrove trees occupied by hermit crabs in the study area for wind speeds between 0 and 5 (Beaufort scale). Regression line equation: no. of trees occupied = -1.44 (wind speed) +12 . ANOVA, $F=18.8, p<0.02$ which had a number of individuals present. The result of such 'shell markets' in arboretum was that some individuals ( $n=5)$ were occasionally observed to leave holes without a shell, with the associated shell being left in the hole. Less occasionally $(n=2), C$. cavipes individuals without shells were observed to climb trees, enter holes and join shell markets. C. rugosus were not observed to participate in shell exchange or congregate in tree holes within the study location, but were observed carrying out similar practices in terrestrial trees away from mangrove areas, where C. cavipes was not present.

\section{DISCUSSION}

Coenobita cavipes and C. rugosus are essentially ground living, largely nocturnally active land crabs living within $100 \mathrm{~m}$ of high water levels on tropical and subtropical Indo-Pacific land masses. A proportion of their populations has sometimes been recorded as diurnally climbing trees as an alternative to sheltering in crevices or burrows. On the shores of Quirimba Island, northern Mozambique, hermit crabs are generally the most abundant macro-crustaceans throughout the entire intertidal zone in a variety of habitats. With the exception of 


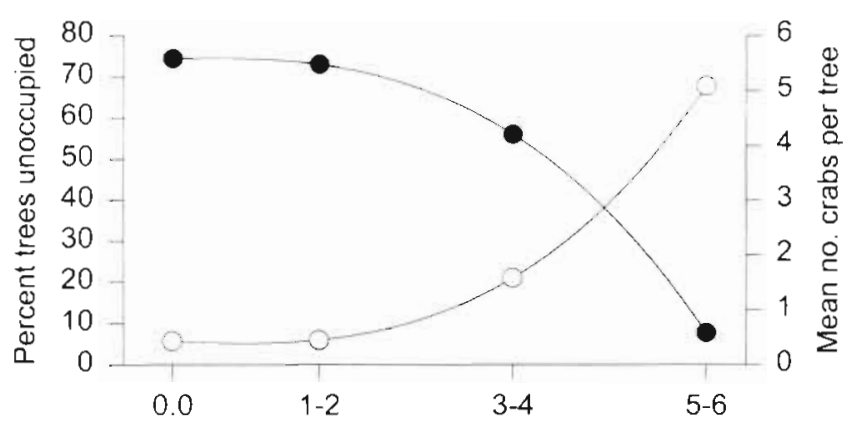

No. holes in tree

Fig. 4. Coenobita cavipes and Coenobita rugosus. Influence of trunk holes on tree climbing of hermit crabs. (-) Proportion $(\%)$ of trees in the study area unoccupied. (O) Mean number of crabs per tree

the Uca annulipes communities (D. K. A. Barnes \& P. Hogarth unpubl.), C. cavipes and C. rugosus were the most abundant supra-littoral dwelling macro-crustaceans at Quirimba Island, both on the ground and in trees. Various Metopograpsus, Grapsus and Sesarma species were also present in mangrove trees but more so in the upper shore, rather than supra-littoral zone, and in comparatively much lower population densities. Clibanarius longitarsus, another species of hermit crab frequenting the supra-littoral zone at Quirimba Island, was not observed to vertically migrate up trees in the study location, although the behaviour has been reported at other locations (Johnson 1965, Macnae 1968).

Both Coenobita cavipes and C. rugosus were found to regularly climb the trunk as well as the root systems of mangrove trees. Occasionally, small branches were climbed and the canopy layer reached. The tree climbing habit was more prevalent in $C$. cavipes than $C$. rugosus (Table 1), but both species occurred in trees at all stages of the light:dark cycle and tidal conditions (Tables 2 \& 3). Within a mangrove tree, the range of both species extended beyond the root system, trunk and branches to the leaves themselves, a distribution unusual amongst mangrove crabs (Vannini \& Ruwa 1994). C. Cavipes and C. rugosus at Quirimba Island also differed from most tree climbing crabs in that they exhibited no obvious tree climbing mass migration pattern. At other locations the general activity pattern of these species, as with other species of the Coenobitidae, has been described as nocturnal apart from in exceptionally humid circumstances (Ball 1972, Alexander 1976, Vannini 1976).

At Quirimba Island, mangrove dwelling Coenobita cavipes and $C$. rugosus may remain active throughout the day, and only the populations living on very exposed sand beach diurnally migrated to refugial shelter (Barnes 1997). Despite such extended activity patterns, the number of hermit crabs climbing or present in trees was greatest during diurnal high water periods (Table 2). This suggested a refugial element to tree climbing, partly in direct escape from high water and partly to avoid having to leave shade (by crawling upshore and inland) to avoid high water Large $C$. cavipes and Ocypode ceratopthalmus (amongst other species) were observed to eat smaller C. cavipes and C. rugosus individuals. As this behaviour was mostly nocturnal and predators did not climb or did not climb high, nocturnal climbing by smaller $C$. cavipes and $C$. rugosus would potentially reduce predation. Climbing trees and migrating to the branch and leafy termini of trees reduces predation in the brachyuran crab Sesarma leptosoma (Vannini \& Ruwa 1994). Despite such migrations, some of its brachyuran predators (species which also occur at Quirimba Island and are probably also hermit crab predators) have been observed to climb occasionally and prey on $S$. leptosoma in trees (Vannini et al. in press). However, the numbers of hermit crabs present in trees at all circadian and tidal stages (Table 2) and the duration of presence in trees (up to $24 \mathrm{~h}$, see Fig. 1) also suggest other factors must influence such behaviour.

The actual height attained by tree climbing species is rarely measured: previous studies of decapods have tended to focus on the number of crabs and the direction of migration (Warner 1967, Von Hagen 1977, Vannini \& Ruwa 1994). The measurements of hermit crab climb height taken in this study illustrate that a number of behavioural subtleties can be gained from such information. The climb height of Coenobita cavipes and $C$. rugosus individuals ranged from $5 \mathrm{~cm}$ to $4 \mathrm{~m}$ and were higher in the former species. The height climbed by $C$. cavipes and $C$. rugosus individuals was greater at high water than low (but only by approximately $24 \%$, see Table 3) and only trees up to $10 \mathrm{~m}$ each side of the High Water Mark (HWM) were climbed. Climb height was, however, unrelated to the shore position of the tree climbed (within the zone) and whether the tide actually reached the tree (Table 4). The climb height pattern thus conflicts to some extent with current hypotheses regarding climbing and avoidance of sea water immersion and suggests that immersion avoidance only partly explains and alters the vertical migration of $C$. cavipes and $C$. rugosus.

Mean climb height was related to the size of Coenobita cavipes individuals, such that maxima were achieved by those of mid-sized mass ( $4 \mathrm{~g}$; Fig. 2). This is probably a result of a combination of energetics and predation. In small specimens the shell is a higher proportion of total mass and hence more expensive energetically to carry vertically. However, larger specimens of both species have outgrown their brachyuran (and cannibalistic) predators and were observed to be more 
regularly immersed in sea water, suggesting greater tolerance and thus less need for mangrove tree climbing. These observations are thought to be the first reports of regular complete immersion by these semiterrestrial species. The mean climb height and behav iour of hermit crabs carrying different molluscan shell species differed (Table 5), but in the former case may just be effect of individual size (as different shell species are preferentially used by differently sized hermit crabs). Certain shells must, however, have attributes more suitable to climbing than others, such as a squat and relatively light structure. Such a structure is typified by the shell of the mollusc Turbo coronatus, which was twice as common amongst tree climbing individuals of $C$. cavipes than in those of the ground population (Table 5). Conversely, tall spired, heavy shells such as those of Terebra, Mitra and Fasciola spp. should prove unpopular for climbing. Of these types (which are all used by Quirimba Island hermit crabs), only Fasciola trapezium was used by $C$. cavipes and $C$. rugosus and it was only half as common amongst tree climbing individuals as those sampled on the ground.

Environmental factors that have previously been investigated as affecting land crab distribution include temperature, ion availability and water availability (reviewed in Burggren \& McMahon 1988). At Quirimba Island, wind speed affected local distribution of Coenobita cavipes and C. rugosus. Wind speed above a critical level (approximately force 3 or 11 to $12 \mathrm{~km}$ $\mathrm{h}^{-1}$ ) had a major influence on tree climbing, significantly reducing the numbers of hermit crabs per tree (Fig. 3a). The switch from tree climbing (and all other activity - see Barnes 1997) to ground refugia will largely be related to desiccation avoidance (and so indirectly water availability, above). Shell damage avoidance may also be a contributing factor, as climbing trees in a thin mangrove forest exposed to wind could potentially result in individuals being blown off branches. The nature of mangrove trees also had an important influence on the probability of a given tree being climbed and the number of hermit crabs climbing it (Fig. 4). Whilst the only recorded attribute of trees to have notable influence was that of trunk/ branch holes, at least in part this influence, like that of wind, is related to water retention. C. rugosus is known to prefer to carry fresh water rather than sea water in its shell, although $C$. cavipes has usually been described as filling its shell with sea or brackish water (Gross et al. 1966, Alexander 1976). At Quirimba Island, however, most $C$. cavipes were rarely seen entering the sea and preferred to fill their shells with fresh water (except for the larger individuals). Here (as with most islands of the Quirimba Archipelago) pools of rain collecting in tree hollows is one of the only sources of fresh water. Thus trunk/branch holes are an important source of fresh water to hermit crabs, but they are also the only place where hermit crabs gather apart from the occasional cluster around a large food item.

Clustering has been described in a number of East African intertidal species and has been studied in particular detail in the upper/mid shore species Clibanarius laevimanus (Gherardi et al. 1991, 1994, Gherardi \& Vannini 1992,1993). The major function of such clusters is at present debated, but Gherardi et al. (1994) suggested they functioned as 'shell markets' for the inspection and exchange of shells between individuals. For a species such as Coenobita cavipes, which is restricted in feeding time to low tide, food gatherings do represent an opportunity for shell exchange, but by day there are added risks of desiccation and by night predation, and exchange by either day or night would reduce feeding time. In gatherings in tree holes (where up to 30 individuals may be present), shell exchange (1) reduces desiccation (there is sometimes additionally a supply of fresh water), (2) reduces the risk of predation and (3) does not reduce feeding time.

The vertical migration or tree climbing habit of the supra-littoral hermit crabs Coenobita cavipes and $C$. rugosus at Quirimba Island is clearly not merely a refugial retreat, but a complex behavioural trait. The timing and period of tree climbing, the height climbed, and the number of individuals per tree and the particular trees climbed are related to a variety of environmental and biotic factors. Major influences are tidal rhythms, wind speed, nature of the particular tree climbed and hermit crab identity, and other influences are the light:dark cycle, position of the particular tree climbed, hermit crab mass and the type of shell carried

Acknowledgements. The author thanks the scientific and logistic staff and volunteer research assistants of the Darwin/ Frontier Mozambique Marine Research Programme. This is a collaborative venture between the Society for Environmental Exploration and the Ministépara a Coordenação de Acçào Ambiental (MICOA) in Mozambique and is partly funded by the Darwin Initiative for the Survival of Species (Department of the Environment, UK). I also thank Dr Richard Hartnoll and Dr Peter Convey for advice and Damon Stanwell-Smith for being instrumental in the travel to Mozambique.

\section{LITERATURE CITED}

Alexander HGL (1976) An ecological study of the terrestrial decapod Crustacea of Aldabra. PhD thesis, University of London

Ball EE (1972) Observations on the biology of the hermit crab Coenobita compressus H. Milne Edwards (Decapoda, Anomura) on the west coast of the Americas. Rev Biol Trop Biol 20:265-273

Barnes DKA (1997) Ecology of tropical hermit crabs at Quirimba Island, Mozambique: distribution, abundance and 
activity. Mar Ecol Prog Ser 154:133-142

Burggren WW, McMahon BR (1988) Biology of the land crabs. Cambridge University Press, Cambridge

De Wilde PAWJ (1973) On the ecology of Coenobita clypeatus in Curacao with reference to reproduction, water economy and osmoregulation in terrestrial hermit crabs. Stud Fauna Curacao Other Carib Isl 44:1-138

Gherardi F, Micheli F, Vannini M (1991) Preliminary observations of the clustering behaviour of the tropical hermit crab, Clibanarius laevimanus. Ethol Ecol Evol 1:151-153

Gherardi F, Vannini $M$ (1992) Hermit crabs in a mangrove swamp: clustering dynamics of Clibanarius laevimanus. Mar Behav Physiol 21:85-104

Gherardi F, Vannini M (1993) Hermit crabs in a mangrove swamp: proximate and ultimate factors in the clustering of Clibanarius laevimanus. J Exp Mar Biol Ecol 168:167-187

Gherardi F, Zatteri F, Vannini M (1994) Hermit crabs in a mangrove swamp: the structure of Clibanarius laevimanus clusters. Mar Biol 121:41-55

Gross WJ, Lasiewski RC, Dennis M, Rudy PP (1966) Salt and water balance in selected crabs of Madagascar. Comp Biochem Physiol 17:641-660

Johnson DS (1965) Land crabs. J Malaysian Branch R Asiatic Soc 38:43-66

Lewinsohn $\mathrm{CH}$ (1982) Researches on the coast of Somalia.

Editorial responsibility: Otto Kinne (Editor).

Oldendorf/Luhe, Germany
The shore and the dune of Sar Uanle. 33. Diogenidae, Paguridae and Coenobitidae (Crustacea, Decapoda, Paguridea). Monit Zool Ital. 2:35-68

Macnae W (1968) A general account of the fauna and flora of the mangrove swamps and forests of the Indo-West Pacific region. Adv Mar Biol 6:73-270

Ruwa RK (1990) The effect of habitat complexities created by mangroves on macrofaunal composition in brackish water intertidal zones at the Kenyan coast. Discovery Innovation 28:49-55

Vannini M (1975) Research on the coast of Somalia. The shore and the dune of Sar Uanle. 5. Description and rhythmicity of digging behaviour. Monit Zool Ital 6:233-242

Vannini M (1976) Field observations on the periodical transdunal migrations of the hermit crab, Coenobita rugosus Milne Edwards. Monit Zool Ital 7:145-195

Vannini M, Ruwa RK (1994) Vertical migrations in the tree crab Sesarma leptosoma (Decapoda, Grapsidae). Mar Biol 118:271-278

Vannini M, Ruwa RK, Olvoch A (in press) The tree climbing crabs of Kenya (Crustacea, Decapoda). Trop Zool

Von Hagen HO (1977) The tree climbing crabs of Trinidad. Stud Fauna Curacao Other Carib Isl 54:25-59

Warner GF (1967) The life history of the mangrove tree crab Aratus pisoni. J Zool Lond 153:321-335

Submitted: May 22, 1997; Accepted: August 21, 1997

Proofs received from author(s): October 15, 1997 